\title{
The Biosphere: A Decadal Vision
}

\author{
David L. Peterson, NASA Ames Research Center, Moffett Field CA 94035 \\ Paul J. Curran, Southampton University, Southampton, UK \\ Marty Mlynzcak, Langley Research Center, Hampton VA 23681 \\ Richard Miller, Stennis Space Center, MS 39529
}

\begin{abstract}
I. INTRODUCTION
While space scientists renew the hunt for a living planet, Earth science has launched the grandest study ever conceived of the only living planet we know, our home planet Earth. This study is truly one at a planetary scale involving programs and people from around the world and technologies and modeling barely envisioned just 25 years ago. Earth startlingly differs from our solar system neighbors because of the presence and power of life, life which influences virtually every system on Earth. Biospheric processes on the land, in the coastal zone and in the open ocean exert an influence on Earth's climate system and climate, in turn, exerts a strong effect on the biosphere and how it is structured and functions. The biosphere, and life in general, depend to a great extent on the presence of liquid water. Changes in climate as well as changes in the biosphere are beginning to affect many aspects of the Earth's hydrologic systems, in particular the delivery of one of the smallest fractions, fresh water. These interactions have a new and complicating force, the transformational power of the growing human population and spirit. And, ultimately, how these changes influence the fate and health of the human population is itself compelling.

To a great extent, the space agencies have pursued an old and familiar object, the climate system. From the earliest days of space observations, Earth's weather and climate systems have focused the attention of agencies and the public. And, still today, to a large extent the central focus of the space-based global science programs are concentrated on the climate system. The focus is different in the International Geosphere Biosphere Programme, a founding program of the study of global change. While climate effects and influences are clearly stated, there is a greater balance between geospheric and biospheric concerns. One of the net effects is a loss of priority in the space camp for observations needed for a fuller study of the biosphere.

This paper focuses on biosphere-climate interactions including the influences of human activities. Recognizing this is only one aspect of biospheric processes, this places an emphasis of those biogeochemical processes that have a profound effect on numerous other aspects of the biosphere and the services it provides, services which are critical to sustaining life on Earth. And, the paper will focus on the various scientific aspects of assessing the availability of fresh water, including its sensitivity to climate variance and land use changes. Finally, this paper hopes to emphasize the potential role that greatly expanded space observations
\end{abstract}

and interactive modeling can play in developing our understanding of Earth and its the living systems.

Ecological principles were laid down only a few decades ago with the 1929 publication of the book by Vernadsky.[1]. Ecology is the science of how the Earth's vegetation and animals assemble into organized internally competing systems interacting within environmental constraints. The co-evolution of ecosystems with the environment provides many clues to our future. Today, for the first time, satellites can measure in a routine way some key properties of ecosystems. These observations are enabling the prediction of a number of important processes: land use, land cover, parts of the carbon and water budgets, and carbon exchange with aquatic systems. But, the required satellite observations needed is far from complete. Just to permit a knowledgeable analysis of how the biosphere, water cycle and the climate system interact with an assessment of the influences of human actions demands much more than is currently planned. Further, a more robust satellite program is required to address the manner in which this knowledge can be used to sustain support for all of Earth's living systems, including humans. The long lead time for satellite programs means the low priority currently being afforded to advanced remote sensing for biospheric measurements will stretch the time needed to gain a complete global understanding of this interaction.

While the biological systems of the open ocean and the coastal zone are vital to understand and predict, the availability of fresh water is a growing international and policy concern. As Matthews [4] articulates so clearly, resources will become an increasingly important part of future national security policy, with the access to and maintenance of fresh water supplies one of the most urgent. Mirroring the growth of human population and technology, human demands for fresh water for agriculture and household uses has been growing dramatically these last 50 years. Climate change and global warming can alter the patterns of precipitation delivery, timing, state and quantity in ways that are likely to exacerbate fresh water supplies. Impoundments and diversions are a supply solution with their own consequences, including the diversion of silt away from the coastal environments as well as the total amount of fresh water to mix with salt water. The cleansing of water is a function of the ecosystem in the contributing watersheds. The effects of human manipulation of terrestrial ecosystems worldwide has impacts on fresh water quality and amount that are not well understood. And, the control of fresh water systems has important effects on the biological systems in 
wetlands, streams, lakes and rivers that depend on evolutionary adaptations to the characteristics of these systems. Lastly, human interactions with fresh water organisms can have profound human health implications. Many vectors of infectious disease, such as malaria, schistosomiasis, cholera and more have a critical link to the patterns and condition of fresh water systems.

\section{CURRENT PLANS (NEXT DECADE)}

There is quite a bit of consensus among international programs on research priorities for terrestrial ecosystems, the coastal zone, and the open ocean. A significant portion of these objectives concern the interactions of the structure and function of ecosystems with the climate system and changes in it, and the added complications of the human dimensions. For example, the objectives of long-term programs of the International Geosphere Biosphere Programme (IGBP) address this question including Global Climate and Terrestrial Ecosystems (GCTE), Global Environmental Change and Food Systems (GECaFS), and Biospheric Aspects of the Hydrological Cycle (BAHC). Recently, IGBP initiated the Integrated Land Ecosystem-Atmosphere Processes Study (ILEAPS) whose goals is "to provide understanding of how interacting physical, chemical and biological processes transport and transform energy and matter through the land-atmosphere interface." The second phase of IGBP's Land Ocean Interactions in the Coastal Zone (LOICZ) Program addresses five themes: (1), river basins and human dimensions; (2), coastal development and change: Implications for land/sea use; (3), fate and transformation of materials in coastal and shelf waters; (4), towards system sustainability and resource management; and, (5), vulnerability of coastal systems and human safety. The IGBP maintains other studies of the ocean including the Joint Global Ocean Flux Study concerned with the fluxes of materials and energy between the ocean and the atmosphere. The United States Global Change Research

Program (www.usgcrp.gov, Changing Ecosystems chapter), as well as the U.S. Climate Change Research Program (USCCRP), is focused on climate with substantial attention on biosphere interactions. Under USGCRP, regarding the reduction of uncertainties in climate prediction, the sensitivity to unresolved ocean processes is of particular note. "Because of computer resolution, none of the current coupled climate models resolve the small ocean eddies (with horizontal scales of tens of kilometers) that constitute the dominant scale of oceanic variability. These eddies are thought to play a substantial role in regulating oceanic heat transport (via boundary currents) and heat and carbon storage by regu-lating transport to deep waters. A series of eddy-resolving global ocean sensitivity studies are required to assess how well the parameterization of in current climate models portray the ocean's sensitivity to forcing." This planning document says "climate sensitivity is a measure of the climate's response to a unit change in radiative forcing due, for example, to changing atmospheric concentrations of greenhouse gases. It accounts for a major part of the uncertainties in climate projections." One of the long-term questions of the USGCRP Changing Ecosystems program element is "how do natural and human-induced changes in the environment interact to affect the structure, functioning, and services of ecosystems at a range of spatial and temporal scales, including those functions that can in turn influence regional and global climate."

The National Science Foundation of the U.S. has a research program originally called the Freshwater Initiative to initiate research on many aspects of fresh water hydrology, watershed health, and freshwater ecology. The USGCRP Global Water Cycle Program Element lists these focus areas: (1) the effects of large-scale changes in land use and climate on the capacity of societies to provide adequate supplies of clean water; and, (2) how natural processes and human activities influence the distribution and quality of water within the Earth system and to what extent the resultant changes are predictable. The USCCRP reiterates these, adding concern about the movement of sediments, biogeochemical and toxic subtances, and nutrient transport. These programs stress the need for research to inform policy debates and enter decision processes for water management.

IGBP recently completed the Biospheric Aspects of the Hydrologic Cycle, integrating parts into the ILEAPS and Global Energy and Water Cycle Experiment (GEWEX) of the World Climate Research Program. Much of the research was concentrated on the water balance and role of vegetation in regulating that balance.

The European community, while largely in agreement with the biosphere-climate interactions as discussed in NASA's 2030 vision, has three important areas of divergence. First, what is the role of agricultural lands and not just semi-natural vegetation, in the study of biosphere/ climate interactions? Remote sensing has a role to play at the scale of the field and farm where environmental changes in space and time are relatively small, ground data are plentiful and environmental understanding is already strong. Increasingly, however, it is being used at the regional to global scale where environmental changes in space and time are relatively large, ground data are sparse and environmental understanding is non-existent to poor [3]. At the field to farm scale remotely sensed data are often useful but at the regional to global scale they can often be the only data source and so are vital. This facility to provide internally consistent synoptic data at a range of scales has given agricultural remote sensing a major rôle in answering two of the largest (and interlinked) questions of our time: 'How does our planet work?' (i.e., how does the Earth system function, how is it changing and what are the consequences for life on Earth? [5]) and 'whither sustainable agriculture?' (i.e., how do we invent a future in which food security is achievable for all in an environmentally stable way?[2]).

Second, there is an uncertainty about our ability to produce a law-like Earth System Model. A vision of the Earth Science Enterprise is long term prediction. Such predictions could include the effect of climate change on crop yield, insect populations and storm frequency at some 
place and time in the future. Such predictions would be need-driven and would necessitate a change in approach. While prediction is linked epistemologically and historically to science it is not essential and is just becoming a part of the biological/Earth science tradition that characterizes much agricultural/environmental research. This raises conceptual difficulties for formulating and promoting an Earth system modeling agenda. The lay/ political audience who ultimately support such research do so in the hope that piece by piece we can understand how our planet works and when we know then we will know what it will do many years hence. However, the Earth is complex, every relationship is dependent on external influences, so that longterm predictions defy testing [1]. Thus, this research may be unlikely to result in law-like predictions. The emphasis is more likely to be on the use of model-derived estimates with uncertainties $[8,10]$ within a need-driven technological approach (NASA, 2002). and third, most importantly, the importance of sustainable development as a political vehicle for Earth observation developments is paramount.

Both the IGBP and the USGCRP explicitly state the role of space observations in achieving a global view of biosphere-climate interactions. For the United States, the agency charged with providing the satellite observations is largely NASA. NASA is in the midst of launching the Earth Observing System (EOS) to provide a comprehensive data set of climate relevant variables. The priorities of NASA's Earth Science Enterprise have been concentrated on climate change and solid Earth/natural hazards research (NASA, 2000). This will remain the focus for the next ten years as NASA works with its public and commercial partners in the U.S. and internationally to provide the first long term data base of 24 key parameters. The program is organized to get answers to questions in six specific focus areas: (a) How can predictions of climate variability and change be improved? (b) How will future changes in atmospheric composition affect ozone, climate, and air quality? (c) How will carbon cycle dynamics and terrestrial and marine ecosystems change in the future? (d) How will water and energy cycle dynamics change in the future? (e) How can weather forecast duration and reliability be improved? and (f) How can our knowledge of Earth surface change be used to predict and mitigate natural hazards?

\section{NEAR TERM SCIENCE PROGRAMS}

\section{Terrestrial and Marine Ecosystems:}

The ten year U.S. research program in ecosystems stresses the carbon exchange dynamics of North America's terrestrial ecosystems and the open ocean. While NASA's biosphere programs are linked with those of the National Science Foundation and other U.S. agencies. The recent NASA program has made substantial progress. A long-term observational program has been developed to generate "climate quality" information on ecosystems, primary productivity, and carbon properties (e.g., ocean color, veg index and land cover). Various satellite data driven analyses of the major seasonal and interannual variations in terrestrial productivity have shown a world-wide trend of increasing length of growing season above 40 degrees $\mathrm{N}$ lat. A global Landsat data base for quantitative assessment of land cover has been created. Models of ecological and bio-geochemical cycling have been established that use remote-ly sensed parameters. A fire occurrence product is posted daily from Terra MODIS data. Global ocean chlorophyll and sea surface temperature are being assembled from two satellites, SeaWiFS and Terra MODIS. These data are being used in models of open ocean carbon exchange.

Over the next ten years, emphasis will shift to quantifying the seasonal and interannual variations in the state of carbon sources and sinks including the coastal ocean and the Southern Ocean. A new satellite, the Orbital Carbon Observatory, will be launched to measure atmospheric profiles of $\mathrm{CO} 2$ as a constraint on carbon budgets. Carbon assimilation models will be expanded to incorporate new understanding of tropical ecosystems and to couple models with ocean and atmospheric processes (teleconnec-tions). The remote sensing of ecosystems will focus on identification and characterization of plant species functional groups and physiological state for the land, algal blooms and carbon sequestration for marine ecosystems, and forecasts of how ecosystems will respond to multiple stressors. And, repeated Landsat inventories will help to determine the trends in land use change, its causes and the trajectories of response, and the consequences for carbon storage and sequestration. Much of this work is aimed at providing scientifically sound information for policy setting and for decision support systems to implement policy and other land/ocean management objectives.

\section{Freshwater systems:}

While one of the focus areas of the NASA program is the water cycle, the ultimate aim of this research is not to determine the regional distribution of fresh water availability. Instead it focuses on the role of water and energy in the global climate system with aims to improve the prediction and measurement of precipitation, evaporation rates and so forth. A few groups have used digital terrain model data to assemble systems to map hydrologic patterns down to small watersheds. The prediction of water yield from vegetated watersheds has been successful from small catchments to very large river systems. In general, the uses of remote sensing to characterize fresh water yield and quality, to forecast drought or flooding, to assess effects of changes in water flow volumes on fisheries and other aquatic systems is still largely undeveloped.

\section{A DECADAL VIEW}

Looking out to 2030, will the present suite of satellite sensors and research foci be sufficient to answer the questions of how the biosphere and the climate system interact, what the availability of fresh water will be, and what the influences will be from human actions? Probably not. By early in the next decade, the science understanding of the carbon cycle will be greatly improved but it will still 
lack critical measurements. Certainly net primary production will be further along, but probably not, net ecosystem production in which there is an explicit estimation of belowground respiration and maybe not, maintenance respiration. There will be an enhanced global understanding of $\mathrm{CO}_{2}$ and water vapor exchange and $\mathrm{CH}_{4}$ production and consumption; but not other important trace gases: $\mathrm{N}_{2} \mathrm{O}, \mathrm{NO}, \mathrm{CO}$, NMHC, VOCs, and $\mathrm{NH}_{3}$. What biogeochemical processes regulate these fluxes? Are these processes measurable by remote sensing and how much do human actions affect them? And, some progress can be expected on estimating precipitation and some components of the water cycle.

One of the most evident effects of human activity is the transformation of the landscape into uses almost exclusively for the benefit of humankind. At present we can lay down an historical record of land cover and try to infer land use. But we are not well prepared to predict the course of ecosystem restoration or the trajectory of response, nor the possibilities that an ecosystem will enter a new and stable state resistant to restoration. And, what will be the consequences of these changed landscapes and the ecosystem services they are supposed to provide for the generation of fresh water supplies?

Another event as old as the ages is fire, a force now dominated by humans today with tremendous transformation power. Fires produce substantial though poorly understood fluxes of gases and particulates into the troposphere; and can lead to permanent change in ecosystem structure and function. It is also an agent for beneficial change in fire- adapted ecosystems. Hillslopes denuded of vegetation have dramatically reduced capability to absorb rainfall, so that large mass flows can follow fires, clogging reservoirs and rivers, and reducing water quality. Current sensors are incapable of measuring the most important properties of fire, those with predictive power, even though these sensors can provide a rough estimate of fire occurrence.

The coastal zone has been largely neglected in satellite planning. Sensors optimized for the open ocean have limited utility in the shallower and often turbid waters of the coastal zone, a marine system closely coupled to the land. These two ecological domains do share some common unmet measurement needs, namely, mixed layer depth, nutrient fields, salinity, and physiolog-ical state. Though a number of organizations have stated their intention to launch satellites to monitor the coastal zone, as of 2003, none have succeeded (Peterson et al., 2003).

The new or additional measurement requirements for the biosphere are listed in table 1. Though there is discussion of some of the space technology to make these measurements and even some low Technology Readiness Level space experiments (notably, the Hyperion hyperspectral imaging spectrometer on EO-1); NASA does not have a coherent plan to accomplish the difficult suite of measurements described. Commercial companies are now providing some high spatial resolution observations. And, most of these measurements have been demonstrated from airborne platforms, though even those rarely are optimized for specific biological phenomena.

Table 1: New Measurements Required for Biosphere

\begin{tabular}{|l|l|l|}
\hline Measurements & Frequency & Technology Needs \\
\hline OCEANS & & \\
\hline Mixed layer depth, wind fields, salinity & Daily & $\begin{array}{l}\text { Active sensors image through } \\
\text { clouds, lidar sensors }\end{array}$ \\
\hline $\begin{array}{l}\text { Nutrient fields (N, Si, Fe), aerosol deposition, } \\
\text { functional groups }\end{array}$ & Weekly & Passive sensors \\
\hline COASTAL zONE & & $\begin{array}{l}\text { Hyperspectral (350-900nm) (also: } \\
\text { radiometry) }\end{array}$ \\
\hline $\begin{array}{l}\text { Colored dissolved organic matter; Chlorophyll and } \\
\text { other pigments; Functional groups; Bathymetry } \\
\text { and bottom reflectance; Nutrient concentration (N, } \\
\text { Si, Fe, P) }\end{array}$ & Daily-Weekly & $\begin{array}{l}\text { Space-based passive fluorometer } \\
\text { Or excitement/emission fluorometer }\end{array}$ \\
\hline $\begin{array}{l}\text { Physiological state (fluorescence) } \\
\text { TERRESTRIAL ECOSYSTEMS }\end{array}$ & Daily & Libation point (L1) vis-IR sensors \\
\hline Phenological state (leaf out, senescence) & $\begin{array}{l}\text { Hyperspectral and/or special } \\
\text { purpose spectroscopic }\end{array}$ \\
\hline $\begin{array}{l}\text { Biochemical composition of plant canopies (N, } \\
\text { lignin, pigments, etc.); Responses to multiple } \\
\text { stressors (long-term observations) }\end{array}$ & Weekly & $\begin{array}{l}\text { Multispectral thermal with broad } \\
\text { radiometric sensitivity }\end{array}$ \\
\hline $\begin{array}{l}\text { Fire properties (energy release rates, rate of } \\
\text { spread, gas/aerosol loading, soil heating) }\end{array}$ & Daily & LIDAR in repeat missions \\
\hline Standing biomass over time & Monthly-Annual & Technology unknown \\
\hline $\begin{array}{l}\text { Soil properties (one meter soil moisture, carbon } \\
\text { stocks, nutrient availability, hydrologic properties) }\end{array}$ & Weekly & Monthly \\
\hline $\begin{array}{l}\text { Vegetation structure, successional state, primary \& } \\
\text { secondary vegetation condition }\end{array}$ & Hyperspatial multi-spectral \\
\hline
\end{tabular}


Table 2 lists measurement requirements for fresh water assessment. Most of the required measurements are not planned nor do they have priority, except those associated with natural hazards (sea ice thickness, ice sheet thickness, snow pack and ice sheet topographic change). One of the most challenging will be soil moisture, how to assess soil moisture on a continuous basis down to the rooting depth of most plants, about one meter. The only plans going forward today are a combination of in situ sampling and remote sensing for some form of extrapolation.

Table 2. New measurements for Fresh Water Availability

\begin{tabular}{|l|l|l|l|}
\hline Soil moisture & Daily & $<1 \mathrm{~km}$ & $10 \%$ \\
\hline Precipitation & Hourly & $5-25 \mathrm{~km}$ & $5-10 \mathrm{~mm} / \mathrm{h}$ \\
\hline Stream flow & Daily & N.A. & $10 \%$ \\
\hline Sea ice thickness & Monthly & $5 \mathrm{~km}$ & $5 \mathrm{~cm}$ \\
\hline Soil hydrologic properties & Monthly & $<1 \mathrm{~km}$ & N.A. \\
\hline Ocean evaporation rate & Daily & $10 \mathrm{~km}$ & $5 \%$ \\
\hline Reservoir and aquifer volumes & Monthly & scale to basin & $0.1 \mathrm{~mm} / \mathrm{yr}$ \\
\hline Ice sheet thickness & Weekly & $<1 \mathrm{~km}$ & $1 \%$ \\
\hline Snow pack & Weekly & $<1 \mathrm{~km}$ & $0.1 \mathrm{~mm} / \mathrm{yr}$ \\
\hline Ice sheet topographic change & $<1$ year & $1-10 \mathrm{~km}$ & $1 \mathrm{~cm}$ height \\
\hline
\end{tabular}

New Modeling Required

Gross primary production models of the open ocean are based on absorption of photosynthetically active radiation in the photic zone and on the sea surface temperature. The future models will include functional groups with different rates of efficiency, mixed layer depth, nutrient fields ( $\mathrm{N}, \mathrm{Si}, \mathrm{Fe}$ ), and aerosol deposition. Carbon sequestration to the deep ocean is based on knowledge of ocean heat transport and circulation patterns. Future modeling capabilities must integrate mixed layer depth to elucidate the trophic levels of fish and microbiotic species. Once in the coastal zone, the spatial resolution of many processes decreases. This zone is subject to episodic discharge events from the land, which can change the color of the waters and their clarity. Models will be needed of nutrient redistribution and hypersaline flows. Improvements in bio-optical and radiation transport must be improved, considering the possibility of bottom reflectance signals, Case 2 waters, and riverine inputs.

Ecopyhysiological models of terrestrial ecosystems are improving, on track to predict net primary production and related indices of carbon exchange based on remotely sensed variables. These models are based on short-term processes and while they are being used to predict the production of a host of biogenic gases to and from the atmosphere, they are now based too heavily on correlates to NPP. Modeling of life cycle community structure, based on remote sensing data, is less well developed and eventually must be coupled with the ecophysiological models. Future community models will be needed to predict the trajectories of ecosystem response to change, including climatic, land use, multiple stressors, species invasions and so forth. Radiative transfer models must be improved to enable forward prediction of ecosystem variables from the remote sensing signals. Such models are needed for not only the properties of intact and healthy ecosystems, but for all of the altered and disturbed states caused by natural and human induced causes including fire behavior. As these models mature and are tested against calibrated data, the models should allow researchers to better assess the consequences of human interactions: fires, land conversions, grazing, over-utilization, soil degradation, selective and complete harvesting, acidic precipitation, as well as climate variation. In the end, once such models are integrated with other components of the Earth system model and further intelligence is added on ecosystem services, the modeling suite might be ready to address, in conjunction with the greatly enlarged satellite data set, to address numerous practical questions in the terrestrial biosphere.

Table 3. Summary of short term prediction goals enabled by an Earth System Model in 2030. The prediction goals listed below illustrate the improvements extending from the present capabilities towards those expected, circa 2030.

\begin{tabular}{|l|l|l|}
\hline Today & $\mathbf{2 0 1 0}$ & $\mathbf{2 0 3 0}$ \\
\hline Availability of Water & & \\
\hline $\begin{array}{l}\text { First measurements of some } \\
\text { components of the global } \\
\text { hydrological cycle: Precipitation, } \\
\text { Ice Sheets, SST. }\end{array}$ & $\begin{array}{l}\text { Global precipitation } \\
\text { measurements: Global } \\
\text { atmospheric water vapor } \\
\text { measurements }\end{array}$ & $\begin{array}{l}\text { Global precipitation, H2O, } \\
\text { evaporation, ice sheet extent, } \\
\text { quantitative precipitation } \\
\text { forecasts 1 year out. }\end{array}$ \\
\hline $\begin{array}{l}\text { Allocation of fresh water to mul- } \\
\text { tiple uses poorly understood with } \\
\text { remote sensing .Hydrologic yield }\end{array}$ & $\begin{array}{l}\text { First order estimates of fresh } \\
\text { water allocation and storage } \\
\text { Prediction of the hydro-logical }\end{array}$ & $\begin{array}{l}\text { Modeling of fresh water produc- } \\
\text { tion, regional distribution and } \\
\text { shortages. Modeling of ecosystem }\end{array}$ \\
\hline
\end{tabular}




\begin{tabular}{|c|c|c|}
\hline $\begin{array}{l}\text { of large watersheds partially } \\
\text { understood and modeled }\end{array}$ & $\begin{array}{l}\text { yield and water budgets of } \\
\text { regional to large watersheds }\end{array}$ & $\begin{array}{l}\text { processes that produce fresh } \\
\text { water and affect water quality }\end{array}$ \\
\hline \multicolumn{3}{|l|}{ Biosphere-climate Interactions } \\
\hline $\begin{array}{l}\text { Observations of "climate quality" } \\
\text { ecosystem variables allow } \\
\text { relating net primary production } \\
\text { with carbon balance. }\end{array}$ & $\begin{array}{l}\text { Carbon sources and sinks for } \\
\text { North America for carbon } \\
\text { management decisions based on } \\
\text { reduced uncertainties }\end{array}$ & $\begin{array}{l}\text { Prediction of high resolution, } \\
\text { monthly biosphere-atmosphere } \\
\text { exchange of gases, aerosols and } \\
\text { energy by oceans, coastal zone, } \\
\text { and terrestrial biosphere } \\
\end{array}$ \\
\hline $\begin{array}{l}\text { First-order characterization of } \\
\text { annual biogeochemical cycling } \\
\text { and biospheric processes for } \\
\text { carbon in open ocean and } \\
\text { terrestrial models based on } \\
\text { remote sensing data }\end{array}$ & $\begin{array}{l}\text { Effects of land use change and } \\
\text { biomass recovery on carbon } \\
\text { balance with carbon pools } \\
\text { assessed; and, accurate } \\
\text { measurement of carbon exchange } \\
\text { and pools for the coastal zone }\end{array}$ & $\begin{array}{l}\text { Predictive understanding of the } \\
\text { natural and human-induced } \\
\text { regulatory controls on biospheric } \\
\text { processes (climate variability, } \\
\text { biogeochemical cycles, soil loss, } \\
\text { hydrology, radiation and land- } \\
\text { ocean margins) } \\
\end{array}$ \\
\hline $\begin{array}{l}\text { Knowledge of statistical } \\
\text { teleconnections between climate } \\
\text { variability and indices and } \\
\text { ecosystem responses. }\end{array}$ & $\begin{array}{l}\text { Forecasting of ecosystem } \\
\text { response to climate and weather } \\
\text { variability on interannual and } \\
\text { longer time scales. }\end{array}$ & $\begin{array}{l}\text { Capacity to forecast the human } \\
\text { influences on the biosphere- } \\
\text { atmosphere exchange and } \\
\text { biogeochemical cycles. }\end{array}$ \\
\hline $\begin{array}{l}\text { Coarse resolution, global net } \\
\text { primary production modeling for } \\
\text { terrestrial and open ocean } \\
\text { ecosystems. }\end{array}$ & $\begin{array}{l}\text { Carbon process and carbon } \\
\text { management modeling and } \\
\text { forecasting capability that is } \\
\text { ecosystem specific and accounts } \\
\text { for disturbance processes (fire } \\
\text { and land use to first order). }\end{array}$ & $\begin{array}{l}\text { Predictive, fully interactive bio- } \\
\text { sphere modeling at fine space/ } \\
\text { time scales responsing to climate } \\
\text { variation and human effects (pub- } \\
\text { lic health, productivity, biological } \\
\text { invasions, disaster monitoring, } \\
\text { and ecosystem services) }\end{array}$ \\
\hline
\end{tabular}

\section{CONCLUSIONS}

There is some mis-balance between the priorities of the space programs, particularly NASA, and the international programs such as the International Geosphere Biosphere Program about the appropriate commitment to biospheric and fresh water science. The former is strongly concentrated on climate change and natural hazards for NASA, while the latter has a greater emphasis on all of the aspects of the influence of the living systems on the Earth system. Since satellite programs are generally long lead time programs and costly, it could be some time before this apparent imbalance might be rectified. The study of a living planet at such a planetary scale must give due attention to the living part to make up a legitimate and accurate picture of how the system functions and will evolve into a future dominated by human influences. This paper attempts to illustrate some measurement steps and modeling improvements that might move us toward this more complete picture. And, hopefully, provide the kinds of data and models that will allow us to respond to the changes that are sure to come in the near future.

References: [1] Byerly Jr, R. (2000) Prediction and characteristic times. In Sarewitz, D., Pielke Jr, R.A. and Byerly Jr, $\mathrm{R}$. (eds) Prediction, Science, Decision Making and the Future of the Nation. Island Press, Wash. DC:327-340.
[2] Cartwright, N. ed. (2002) The Big Questions in Science. Johnathan Cape, London.

[3]Curran, P.J. and Foody, G.M. (1994) Environmental issues at regional to global scales. In Foody, G.M. and Curran, P.J. (eds) Environmental Remote Sensing from Regional to Global Scales. Wiley, Chichester: 1-7. [4] Matthews, J.T. 1989. Redefining national security. Foreign Affairs 68(2): 175-185.

[5]NASA. 2000. Exploring our Home Planet: Earth Science Enterprise. NASA, Washington DC.

[6]NASA. 2002. Earth Science Enterprise Applications Strategy for 2002-2012. NASA, Washington DC.

[7] Peterson, D.L.et al. Platform options of free-flying satellites, UAVs or the International Space Station for remote sensing assessment of the littoral zone, Int'l Journal of Remote Sensing, in press, 2003.

[8]Skidmore, A. ed. 2002. Environmental Modelling with GIS and Remote Sensing. Taylor and Francis, London. [9] Vernadsky, V.I. 1998. The Biosphere. Copernicus Books, Jan., 1998 (new translation).

[10] Wicks, T. and Curran, P.J. 2002. Flipping forests: estimating future carbon sequestration of the boreal forest using remotely sensed data. International Journal of Remote Sensing (in press). 